Article

\title{
Pyrvinium Pamoate and Structural Analogs Are Early Macrofilaricide Leads
}

Emma L. Gunderson ${ }^{1}$, Clifford Bryant ${ }^{1}$, Christina A. Bulman ${ }^{1}$, Chelsea Fischer ${ }^{1}$, Mona Luo ${ }^{1}$, Ian Vogel ${ }^{1}$, Kee-Chong Lim ${ }^{1}$, Shabnam Jawahar ${ }^{2}$, Nancy Tricoche ${ }^{2}$, Denis Voronin ${ }^{2,+}{ }^{+}$Christopher Corbo ${ }^{3}$, Rene B. Ayiseh ${ }^{4}$, Faustin P. T. Manfo ${ }^{4}$, Glory E. Mbah ${ }^{4,5}$, Fidelis Cho-Ngwa ${ }^{4}$, Brenda Beerntsen ${ }^{6}$, Adam R. Renslo ${ }^{1}$, Sara Lustigman ${ }^{2, *}$ and Judy A. Sakanari ${ }^{1, *}$

check for updates

Citation: Gunderson, E.L.; Bryant, C.; Bulman, C.A.; Fischer, C.; Luo, M.; Vogel, I.; Lim, K.-C.; Jawahar, S.; Tricoche, N.; Voronin, D.; et al. Pyrvinium Pamoate and Structural Analogs Are Early Macrofilaricide Leads. Pharmaceuticals 2022, 15, 189. https://doi.org/10.3390/ph15020189

Academic Editor:

Christophe Dardonville

Received: 3 November 2021

Accepted: 7 January 2022

Published: 2 February 2022

Publisher's Note: MDPI stays neutral with regard to jurisdictional claims in published maps and institutional affiliations.

Copyright: (C) 2022 by the authors. Licensee MDPI, Basel, Switzerland. This article is an open access article distributed under the terms and conditions of the Creative Commons Attribution (CC BY) license (https:// creativecommons.org/licenses/by/ $4.0 /)$.
1 Department of Pharmaceutical Chemistry, University of California San Francisco, San Francisco, CA 94158, USA; emma.gunderson@ucsf.edu (E.L.G.); clifford_bryant@sbcglobal.net (C.B.); cabulman@dons.usfca.edu (C.A.B.); chelsea.fischer811@gmail.com (C.F.); mona.luo144@gmail.com (M.L.); ian.vogel@irb.usi.ch (I.V.); limitskc@hotmail.com (K.-C.L.); adam.renslo@ucsf.edu (A.R.R.)

2 Molecular Parasitology, New York Blood Center, Lindsley F. Kimball Research Institute, New York, NY 10065, USA; shabnam.mob@gmail.com (S.J.); ntricoche@nybc.org (N.T.); denis.voronin@nih.gov (D.V.)

3 Department of Biological Sciences, Wagner College, Staten Island, NY 10301, USA; ccorbo@wagner.edu

4 ANDI Centre of Excellence for Onchocerciasis Drug Research, Biotechnology Unit, Faculty of Science, University of Buea, Buea P.O. Box 63, Cameroon; rbilingwe@yahoo.com (R.B.A.); faustinpascal@yahoo.fr (F.P.T.M.); gmbah21@googlemail.com (G.E.M.); chongwa_ub@yahoo.co.uk (F.C.-N.)

5 Higher Teacher Training College (HTTC), The University of Bamenda, Bamenda P.O. Box 39, Cameroon

6 Department of Veterinary Pathobiology, University of Missouri-Columbia, Columbia, MO 65211, USA; beerntsenb@missouri.edu

* Correspondence: SLustigman@nybc.org (S.L.); Judy.Sakanari@ucsf.edu (J.A.S.)

+ Current address: Systems Genomics Section, Laboratory of Parasitic Diseases, NIAID, NIH, Bethesda, MD 20892, USA.

Abstract: Onchocerciasis and lymphatic filariasis are neglected tropical diseases caused by infection with filarial worms. Annual or biannual mass drug administration with microfilaricidal drugs that kill the microfilarial stages of the parasites has helped reduce infection rates and thus prevent transmission of both infections. However, success depends on high population coverage that is maintained for the duration of the adult worm's lifespan. Given that these filarial worms can live up to 14 years in their human hosts, a macrofilaricidal drug would vastly accelerate elimination efforts. Here, we have evaluated the repurposed drug pyrvinium pamoate as well as newly synthesized analogs of pyrvinium for their efficacy against filarial worms in vitro and in vivo. We found that pyrvinium pamoate, tetrahydropyrvinium and one of the analogs were highly potent in inhibiting worms in in vitro whole-worm screening assays, and that all three compounds reduced female worm fecundity and inhibited embryogenesis in the Brugia pahangi-gerbil in vivo model of infection.

Keywords: repurposed drugs; pyrvinium pamoate; filarial diseases; macrofilaricides

\section{Introduction}

According to the 2017 Global Burden of Disease Study, over 20 million people worldwide are infected with the filarial worm Onchocerca volvulus, which causes onchocerciasis, and nearly 65 million people are infected with Wuchereria bancrofti, Brugia malayi or B. timori, the filarial worms that cause lymphatic filariasis (LF) [1]. Onchocerciasis, also known as river blindness, is a chronic disease caused by the first larval stage, microfilariae (mf), that are released from female worms residing in subcutaneous tissues. The mf migrate throughout the skin, causing severe pruritus, and when they migrate to the eyes, they induce an inflammatory response that eventually leads to impaired vision and blindness. Lymphatic filariasis (elephantiasis) is also a chronic disease but the pathology is associated with the 
adult stages that induce inflammation that can permanently damage host lymphatic tissues [2]. Symptoms of this disease include chronic pain associated with severe lymphedema typically in the arms, legs, breasts and genitalia. Individuals affected by onchocerciasis and elephantiasis often experience economic hardship, social stigma, and suffering. Together, LF and onchocerciasis cause over 2.7 million years lived with disability (YLDs) to people living in impoverished countries [1].

Significant progress in decreasing the prevalence and transmission of these infections has been made in recent years, largely through annual or biannual mass drug administration (MDA) programs lead by the World Health Organization with drugs that are effective against the microfilarial stage of the parasite [1,3,4]. However, there is still a critical need for safe, effective drugs that kill the adult worms (macrofilaricides) since female worms release millions of $\mathrm{mf}$ over their lifespan (6-14 years for these filarial worms) [5], that infect the blackfly (O. volvulus) and mosquito (LF) vectors, thus perpetuating the life cycle. Another major issue with the current microfilaricides is that ivermectin (IVM) used in both MDA programs is not recommended for MDA in regions co-endemic with another filarial nematode, Loa loa, because individuals with high numbers of $L$. loa $\mathrm{mf}$ are at risk of developing severe adverse reactions [6,7]. Moreover, while current evidence for IVM resistance in O. volvulus is far from definitive, sub-optimal responses to IVM in the treatment of onchocerciasis have been identified, i.e., faster rates of skin repopulation are probably due to decreased effects of IVM on female worm fecundity. Ideally, a macrofilaricide would be used in MDA programs and/or in test and treat strategies to cure infections or hinder fecundity, thereby stopping $\mathrm{mf}$ transmission and thus shortening the time to elimination of these diseases. Presently, the target year for eliminating LF and onchocerciasis is 2030 [8-10].

Previously, we screened a library of FDA-approved drugs and identified the anthelminthic drug, pyrvinium pamoate (PVP), as a potent hit in in vitro filarial worm assays [11]. PVP has been used over the last 50 years to treat pinworm infections (enterobiasis) in children; however, it is not readily bioavailable as it is not appreciably absorbed by the gastrointestinal tract $[12,13]$. Several analogs of PVP were generated in an effort to improve its bioavailability for use in other applications such as treatment for prostate cancer $[14,15]$. Here, we describe the evaluation of PVP as well as several newly synthesized synthetic analogs in which the quinoline ring was reduced to tetrahydroquinoline, substitution patterns on the pyrrole ring were altered, or the potentially oxidation-prone pyrrole ring was replaced by pyrrazole. The present study identified two new analogs, tetrahydropyrvinium (THP) and pyrvinium analog 06 , as the most promising early macrofilaricidal compounds using in vitro phenotypic screens and the Brugia pahangi-gerbil model of infection.

\section{Results}

2.1. Analog 06 Shows a Favorable Inhibitory Profile across Parasite Species and Life Stages In Vitro

PVP, tetrahydropyrvinium (THP), and six other PVP analogs that were modified at the quinoline or pyrrole rings (Figure 1) were initially screened in a B. pahangi adult female motility assay.

B. pahangi adult females are readily accessible from laboratory animals and are used in primary screens to test compounds in vitro. Compounds that inhibit motility of adult female B. pahangi by $>70 \%$ are further tested with O. ochengi adults and $\mathrm{mf}$, as well as $L$. loa mf; they are then prioritized for screening in the O. volvulus pre-adult (L5) assays and $O$. volvulus third-stage larvae (L3) molting assay when compounds are effective in the low micromolar range $(<5 \mu \mathrm{M})$. Six out of the 8 compounds (PVP, THP, 01, 02, 05 and 06) tested with $B$. pahangi inhibited worm motility by $>70 \%$ and had $\mathrm{IC}_{50}$ values in the sub-micromolar range (Table 1). The most potent compound was PVP with an $\mathrm{IC}_{50}$ of $0.3 \mathrm{nM}$. 


\begin{tabular}{|c|c|c|c|c|c|c|c|c|c|c|c|}
\hline Pyrro & Analog & $\mathrm{R}_{2}^{\prime}$ & Ph & Redu & 1 Pyrrol & $\mathrm{R}_{2}$ & Ph & Pyr & e An & $\mathrm{R}_{2}^{\prime}$ & $\begin{array}{l}R_{3} \\
v\end{array}$ \\
\hline ID & $\mathbf{R}_{1}$ & $\mathbf{R}_{2}$ & $\mathbf{R}_{3}$ & ID & $\mathbf{R}_{1}$ & $\mathbf{R}_{2}$ & $\mathbf{R}_{3}$ & ID & $\mathbf{R}_{1}$ & $\mathbf{R}_{2}$ & $\mathbf{R}_{3}$ \\
\hline PVP & $\mathrm{Me}_{2} \mathrm{~N}-$ & $\mathrm{Me}$ & $\mathrm{Me}$ & THP & $\mathrm{Me}_{2} \mathrm{~N}-$ & $\mathrm{Me}$ & $\mathrm{Me}$ & 03 & $\mathrm{H}$ & $\mathrm{Me}$ & $\mathrm{H}$ \\
\hline 01 & $\mathrm{H}$ & $\mathrm{Me}$ & $\mathrm{Me}$ & & & & & 04 & $\mathrm{H}$ & $\mathrm{H}$ & $\mathrm{H}$ \\
\hline 02 & $\mathrm{Me}$ & $\mathrm{Me}$ & $\mathrm{Me}$ & & & & & 05 & $\mathrm{H}$ & $\mathrm{Me}$ & $\mathrm{Me}$ \\
\hline & & & & & & & & 06 & $\mathrm{Me}$ & $\mathrm{Me}$ & $\mathrm{Me}$ \\
\hline
\end{tabular}

Figure 1. Chemical structures of pyrvinium pamoate and its analogs.

Table 1. Results of the in vitro whole-worm assay.

\begin{tabular}{|c|c|c|c|c|c|c|c|c|c|}
\hline Compound & $\begin{array}{l}\text { Brugia } \\
\text { Adult } \\
\text { Females } \\
\text { Inhibi- } \\
\text { tion of } \\
\text { Motility } \\
\text { Day } 3 @ \\
1 \mu \mathrm{M}\end{array}$ & $\begin{array}{l}\text { Brugia } \\
\text { Adult } \\
\text { Females } \\
\text { Inhibition } \\
\text { of } \\
\text { Motility } \\
\text { Day } 3 \\
\text { IC }_{50} \\
(\mu \mathrm{M})\end{array}$ & $\begin{array}{l}\text { O. volvulus } \\
\text { L5 } \\
\text { Inhibition } \\
\text { of Motility } \\
\text { Up to Day } \\
36\end{array}$ & $\begin{array}{l}\text { O. } \\
\text { volvulus } \\
\text { L5 } \\
\text { Inhibition } \\
\text { of Motility } \\
\text { IC }_{50}(\mu \mathrm{M})\end{array}$ & $\begin{array}{l}\text { O. } \\
\text { volvulus } \\
\text { L3 } \\
\text { Inhibition } \\
\text { of } \\
\text { Molting } \\
\text { Day } 6 \\
\text { IC }_{50} \\
(\mu \mathrm{M})\end{array}$ & $\begin{array}{l}\text { O. } \\
\text { ochengi } \\
\text { Adult } \\
\text { Males In- } \\
\text { hibition } \\
\text { of } \\
\text { Motility } \\
\text { Day } 5 \\
\mathrm{IC}_{50}(\mu \mathrm{M})\end{array}$ & $\begin{array}{l}\text { O. } \\
\text { ochengi } \\
\text { Adult } \\
\text { Females } \\
\text { Inhibition } \\
\text { of } \\
\text { Survival } \\
\text { Day } 7 \\
\mathrm{IC}_{50} \\
(\mu \mathrm{M})\end{array}$ & $\begin{array}{l}O . \\
\text { ochengi } \\
\text { Mf } \\
\text { Inhibition } \\
\text { of } \\
\text { Motility } \\
\text { Day } 5 @ \\
10 \mu \mathrm{M}\end{array}$ & $\begin{array}{l}\text { Loa loa } \\
\text { Mf } \\
\text { Inhibition } \\
\text { of } \\
\text { Motility } \\
\text { Day } 5 @ \\
10 \mu \mathrm{M}\end{array}$ \\
\hline 01 & $99 \%$ & 0.008 & $\begin{array}{l}94 \% \text { on Day } \\
36 @ 1 \mu \mathrm{M}\end{array}$ & nd & nd & 0.96 & 0.79 & $100 \%$ & $100 \%$ \\
\hline 02 & $83 \%$ & 0.001 & $\begin{array}{l}90 \% \text { on Day } \\
16 @ 1 \mu \mathrm{M}\end{array}$ & nd & nd & 3.08 & 0.70 & $100 \%$ & $100 \%$ \\
\hline 03 & $3 \%$ & nd & $\begin{array}{l}97 \% \text { on Day } \\
28 @ 10 \mu \mathrm{M}\end{array}$ & nd & 0.14 & 1.54 & 5.18 & $0 \%$ & $13 \%$ \\
\hline 04 & $26 \%$ & nd & nd & nd & nd & $\begin{array}{l}\text { *100\% @ } \\
10 \mu \mathrm{M}\end{array}$ & nd & $0 \%$ & $38 \%$ \\
\hline 05 & $81 \%$ & 0.405 & $\begin{array}{l}92 \% \text { on Day } \\
36 @ 1 \mu \mathrm{M}\end{array}$ & nd & nd & $\begin{array}{l}* 86 \% @ \\
10 \mu \mathrm{M}\end{array}$ & nd & $0 \%$ & $38 \%$ \\
\hline 06 & $71 \%$ & 0.733 & $\begin{array}{l}94 \% \text { on Day } \\
36 @ 1 \mu \mathrm{M}\end{array}$ & $\begin{array}{l}0.22 \mu \mathrm{M} \text { on } \\
\text { Day } 21\end{array}$ & 0.46 & 2.75 & 2.99 & $46 \%$ & $88 \%$ \\
\hline THP & $100 \%$ & 0.003 & $\begin{array}{l}68 \% \text { on Day } \\
36 @ 1 \mu \mathrm{M}\end{array}$ & $\begin{array}{l}<1.0 \mu \mathrm{M} \text { on } \\
\text { Day } 21\end{array}$ & 0.19 & 0.06 & 0.61 & $100 \%$ & $100 \%$ \\
\hline PVP & $82 \%$ & 0.0003 & $\begin{array}{l}100 \% \text { on } \\
\text { Day } 14 @ 1 \\
\mu \mathrm{M}\end{array}$ & $\begin{array}{l}<0.3 \mu \mathrm{M} \text { on } \\
\text { Day } 21\end{array}$ & 0.03 & 0.11 & 0.05 & $\begin{array}{l}100 \% \text { and } \\
* * \mathrm{IC}_{50}= \\
0.3 \mu \mathrm{M}\end{array}$ & $100 \%$ \\
\hline
\end{tabular}

nd = not done; ${ }^{*}$ Assays conducted at only a single concentration $(10 \mu \mathrm{M})$; no further testing done; ${ }^{* *} \mathrm{IC}_{50}$ was also conducted with O. ochengi $\mathrm{mf}$.

The same six compounds also showed strong potency against $O$. ochengi adult males and females, with $\mathrm{IC}_{50} \mathrm{~s}$ in the low $\mu \mathrm{M}$ or sub-micromolar range. Compounds 04 and 05 inhibited motility of male O. ochengi by $100 \%$ and $86 \%$, respectively, at a single concentration 
of $10 \mu \mathrm{M}$ but were deprioritized since 04 was not as potent as the other compounds and 05 had a sub-optimal ADME profile (Table 2).

Table 2. In vitro ADME results. Analog 06 showed improved retention in the gerbil liver microsome assay as compared to its parent compound and the other analogs. PVP and the analogs except for 06 showed rapid clearance from microsomes, indicating that it could be rapidly metabolized in the liver.

\begin{tabular}{|c|c|c|c|c|c|c|}
\hline Compound & $\begin{array}{l}\text { Gerbil Liver } \\
\text { Microsome } \\
T_{1 / 2} \text { (min) }\end{array}$ & $\begin{array}{l}\mathrm{CL}_{\text {int }} \\
(\mu \mathrm{L} / \mathrm{min} / \mathrm{mg} \\
\text { Protein })\end{array}$ & $\begin{array}{l}\text { Mean Papp } \\
\left(\times 10^{-6} \mathrm{~cm} / \mathrm{s}\right)\end{array}$ & $\begin{array}{l}\text { Mean } \\
\text { Papp } \\
\left(\times 10^{-6} \mathrm{~cm} / \mathrm{s}\right)\end{array}$ & $\begin{array}{l}\text { MDCK } \\
\text { Efflux Ratio } \\
\text { B-A/A-B }\end{array}$ & $\begin{array}{l}\text { MDCK Recovery } \\
\text { Rate }(\%)\end{array}$ \\
\hline 01 & 2.3 & 610.8 & 0.1 & 61.3 & 531.9 & 77 \\
\hline 02 & 2.6 & 541.8 & 0.1 & 51.2 & 736.7 & 67 \\
\hline 03 & 4.9 & 280.2 & 1.3 & 9.1 & 7.2 & 104 \\
\hline 05 & 7.7 & 179.88 & 0.7 & 6.8 & 9.3 & 96 \\
\hline 06 & 1484.9 & 0.933 & 0.5 & 12.1 & 23.7 & 94 \\
\hline THP & 14.6 & 95.14 & $<0.25$ & 0.6 & $>2.5$ & 15 \\
\hline PVP & 5.3 & 261.6 & $<0.07$ & 6.6 & $>94.6$ & 69 \\
\hline
\end{tabular}

The microfilariae of O. ochengi and L. loa were screened with all 8 compounds with single concentrations of $10 \mu \mathrm{M}$. PVP, THP, 01 and 02 completely inhibited mf motility, while 03, 04 and 05 had little to no effect on the mf. Analog 06 inhibited O. ochengi mf motility by $46 \%$ and inhibited motility of $L$. loa $\mathrm{mf}$ by $88 \%$ at $10 \mu \mathrm{M}$. Because the number of $L$. loa $\mathrm{mf}$ needed for $\mathrm{IC}_{50}$ assays were not readily available, an $\mathrm{IC}_{50}$ was only conducted for PVP which had a value of $0.3 \mu \mathrm{M}$, a value 3- and 6-fold higher than those for adult male and female $O$. ochengi worms, respectively.

Analogs 03, 06, THP and PVP were also tested in an O. volvulus L3 (Ov L3) molting assay and all four compounds had $\mathrm{IC}_{50} \mathrm{~s}$ in the sub-micromolar range $(<0.5 \mu \mathrm{M}$; Supporting Information Figure S1). Compounds 01, 02, 05, 06, THP and PVP were also tested with O. volvulus pre-adult L5 (Ov L5) at $1 \mu \mathrm{M}$ over 36 days (Table 1, Figure 2). Compounds 01, $02,05,06$ and PVP were highly effective in inhibiting Ov L5 motility ( $>90 \%$ by day 36 ) when treated with $1 \mu \mathrm{M}$, compared to THP (68\% by day 36$)$.

\subsection{Ov L5 Treated with $10 \mu M$ THP In Vitro Show Ultrastructural Damage}

Ov L5 worms treated with THP in vitro were assessed by transmission electron microscopy (TEM) to examine the qualitative effects of drug treatment on the ultrastructural integrity of the worms. The Ov L5 were cultured in vitro to day 78 and then treated for 14 days with $10 \mu \mathrm{M} \mathrm{THP}$, exchanging the media with compound every other day. After the 14 days of treatment, the Ov L5 were kept in fresh media for the next 7 days, with media exchanged every other day. THP treatment caused significant damage as evidenced by the significant vacuolization and necrosis (Figure 3) occurring in worms treated with THP.

\subsection{Analog 06 Demonstrated Acceptable Activity in ADME Studies}

Analogs 01, 02, 03, 05, and 06, as well as THP and PVP were tested for stability in gerbil liver microsomes, and permeability across MDCK monolayers, as a model for intestinal absorption (Table 2). Analog 06 showed the most promise in the gerbil liver microsome assay as it was the only compound with low intrinsic clearance $\left(\mathrm{CL}_{\text {int }}=0.9 \mu \mathrm{L} / \mathrm{min} / \mathrm{mg}\right.$ protein); all other tested compounds had clearance rates $\geq 95 \mu \mathrm{L} / \mathrm{min} / \mathrm{mg}$. All the compounds exhibited very low permeability in the apical to basal direction (MDCK assay), with significant efflux ratios, indicating a propensity for efflux by the P-gp transporter. Nevertheless, because 06 had the best activity against target worms in vitro and overall, had the most promising ADME profile, it was selected for in vivo studies as well as THP and PVP. 


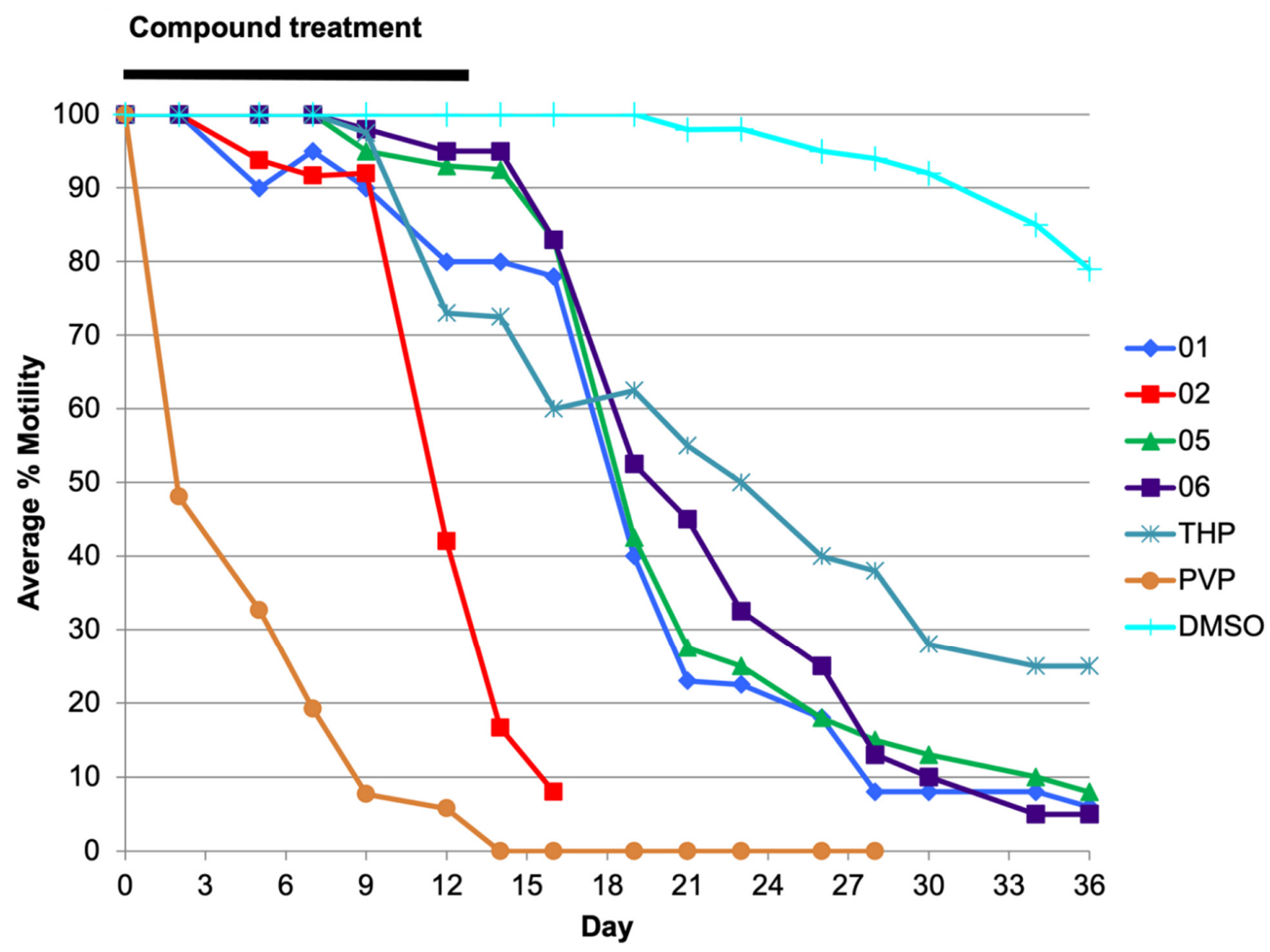

Figure 2. Ov L5 were treated with $1 \mu \mathrm{M}$ of $01,02,05,06$, THP and PVP for 14 days (change of media + drug $50 \%$ every two days) and then with fresh media (change of media $50 \%$ up to day 36 ). PVP treated L5 worms did not recover during this washout period and the assay with analog 02 was stopped on day 16 when contamination was observed. Inhibition of motility was well correlated with inhibition of viability as measured by endpoint MTT assay (Supporting Information Table S1).
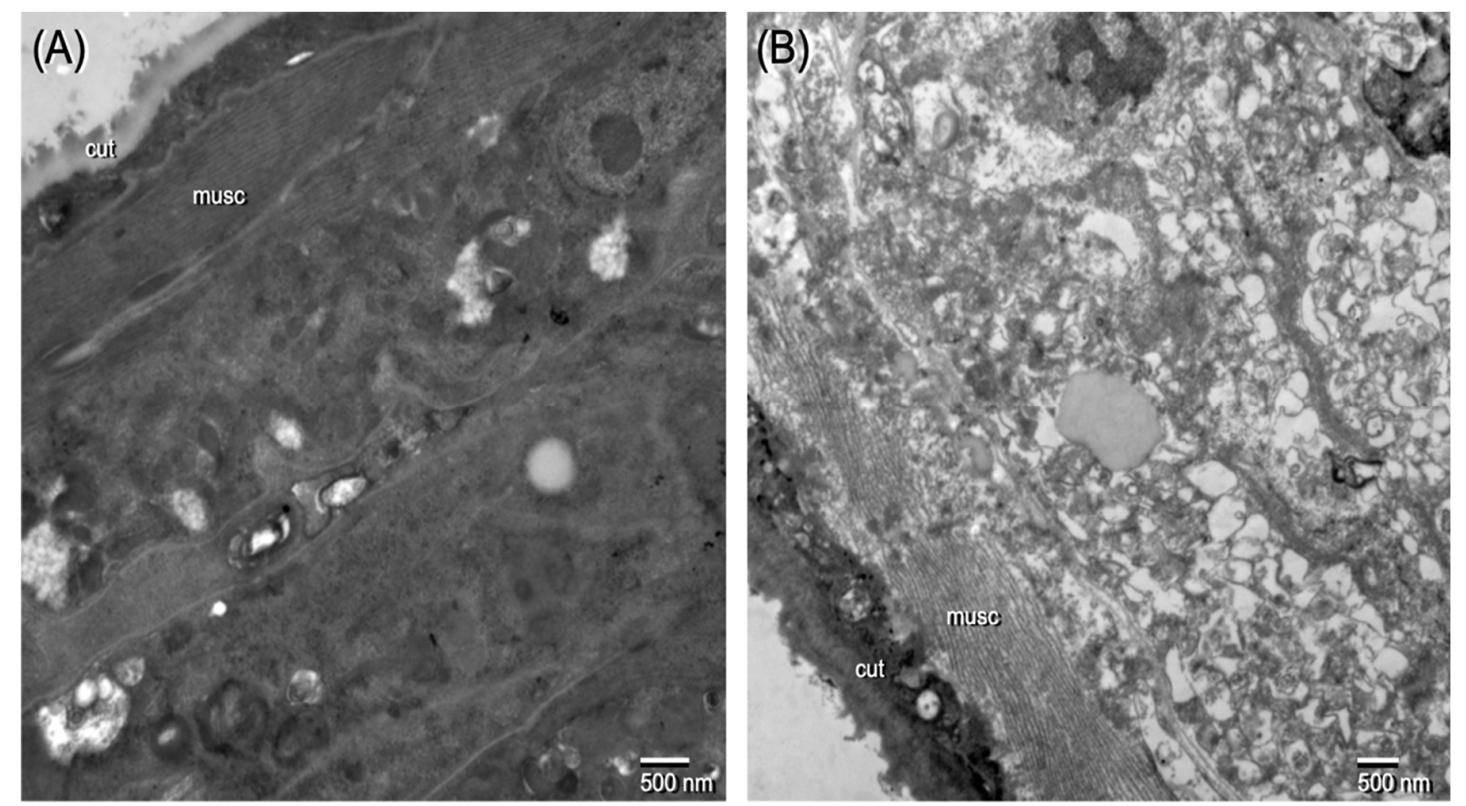

Figure 3. Microphotograph of (A) control and (B) THP treated Ov L5 from an in vitro assay. THP treated Ov L5 show cellular damage: vacuolization of cytoplasm, disrupted morphology of cellular content and cells lacking integrity. cut = cuticle; musc = muscle. 


\subsection{Pyroinium, THP and 06 Reduce Female Worm Fecundity in the Brugia/Gerbil Model}

Animals necropsied 13 weeks post-first dose revealed that adult worm and peritoneal mf numbers were highly reduced $(\sim 95 \%)$ in animals treated IP once a day for 5 days with $1 \mathrm{mg} / \mathrm{kg}$ PVP compared to the control group. Only 6 worms were recovered from animals treated with PVP ( $n=7$ animals; mean $=0.9$ worms) while the animals from the vehicle group had a total of 148 worms $(n=8$ animals; mean $=18.5)$. Although there was no statistical difference between these two groups due to the high variability within each group, the results suggest that PVP impacts worm burdens since approximately 20 -fold fewer worms were recovered from treated animals (Table 3). Wolbachia titers were not significantly different in worms from the treated animals compared to the vehicle group, suggesting that compounds had a direct effect on the adult worms and not an indirect effect on the bacteria (Supporting Information Figure S2).

Table 3. Treatment with PVP reduces adult worm burden and mf levels in the peritoneal cavity. The mean number of adult worms and $\mathrm{mf}$ from animals given $1 \mathrm{mg} / \mathrm{kg}$ PVP IP was reduced by 20- and 100-fold, respectively, compared to vehicle treated animals. Means \pm SEM (in parentheses) are shown.

\begin{tabular}{|c|c|c|c|c|}
\hline & \multicolumn{4}{|c|}{ Dosage of $1 \mathrm{mg} / \mathrm{kg}$} \\
\hline & Vehicle & THP & 06 & PVP \\
\hline Number of animals & 8 & 8 & 8 & 7 \\
\hline Adult worms per animal & $18.5(8.2)$ & $21.9(7.6)$ & $31.3(11.8)$ & $0.9(0.5)$ \\
\hline Female worms per animal & $8.5(3.9)$ & $10.4(4.2)$ & $15.9(5.7)$ & $0.1(0.1)$ \\
\hline Male worms per animal & $10(4.3)$ & $11.5(3.7)$ & $15.4(6.1)$ & $0.7(0.4)$ \\
\hline Mf per animal & $1,271,443(1,092,551)$ & $652,500(326,014)$ & $915,000(263,235)$ & $\begin{array}{l}10,429 \\
(5822)\end{array}$ \\
\hline
\end{tabular}

The mean number of $\mathrm{mf}$ recovered from control animals was $1.27 \times 10^{6}$, while the mean number of $\mathrm{mf}$ from PVP treated animals was $10.4 \times 10^{3} \mathrm{mf}$, which is 100 -fold less compared to the control group, suggesting that PVP also greatly reduced female worm fecundity.

Since only a single female worm was recovered from animals treated with PVP, only female worms from animals treated with THP and 06 were further assessed for the number of $\mathrm{mf}$ shed overnight and embryograms, both indicators of reproductive capacity and fecundity. Female worms from the THP and 06 treated groups released significantly lower numbers of $\mathrm{mf}$ after $24 \mathrm{~h}$ ex vivo ( $p<0.01$ and $p<0.0001$, respectively) (Figure $4 \mathrm{~A}$ ). Embryogram analyses also revealed that there was a significant increase in the number of deformed embryos present in the gonads of female worms recovered from animals treated with THP $(p<0.05)$ and $06(p<0.001)$ compared to the vehicle group (Figure $4 \mathrm{~B})$.

\subsection{THP and Analog 06 Cause Damage to Female Reproductive Structures}

Ultrastructural cell damage was assessed in female worms removed from animals treated with $1 \mathrm{mg} / \mathrm{kg}$ of THP and analog 06 using TEM (only 1 female worm was recovered from animals treated with PVP and was not used for TEM). Results support the embryogram analyses and revealed that the ultrastructure of gonads from worms taken from animals treated with THP and 06 contained developing microfilariae that had abnormal ultrastructural phenotypes compared to the controls (Figure 5). Analog 06 (Figure 5E-H) not only had a more severe effect on the gonads but additional cellular pathologies not seen in the THP-treated worms (Figure 5B-D) were also observed, including abnormal heterochromatin accumulation at the inner surface of the nuclear envelope (Figure 5G, white asterisks). Additionally, nuclear envelopes are juxtaposed to each other (Figure 5E-G, white boxes), with the interchromatin contents of each appearing in close proximity to each other. These changes suggest that breakdown of the nuclear membranes within the microfilariae may lead to the disruption of the nuclear envelope as seen in the higher magnification image (Figure $5 \mathrm{H}$, black arrowhead). 


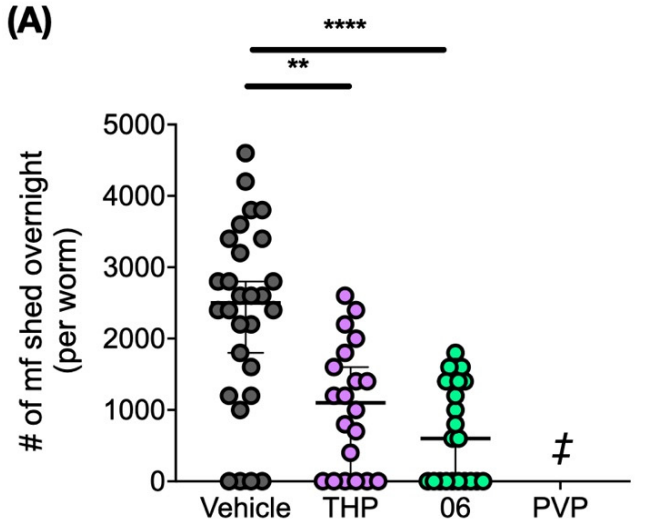

(B)

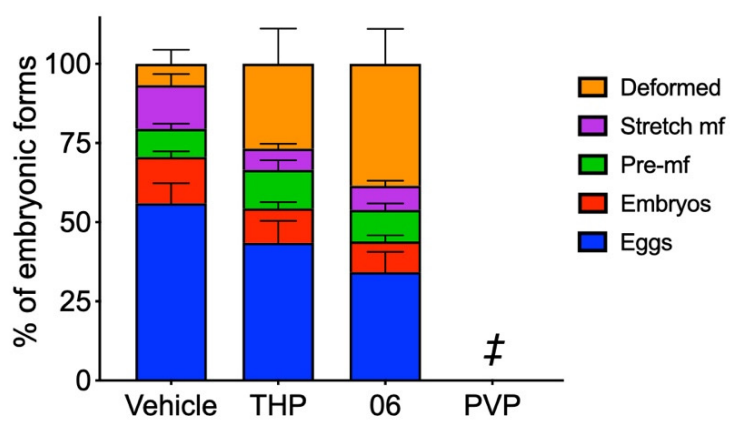

Figure 4. THP and 06 reduce fecundity in female worms recovered from animals treated intraperitoneally with $1 \mathrm{mg} / \mathrm{kg}$. (A) Mf released overnight from females recovered from animals treated IP with $1 \mathrm{mg} / \mathrm{kg}$ THP and 06 was significantly reduced $\left(^{* *}, p<0.01\right.$ and ${ }^{* * *}, p<0.0001$, respectively). (B) THP and 06 impaired embryogenesis: a minimum of 200 embryonic forms within the ovaries and uteri from female worms were counted and scored based on their developmental stages (eggs, embryos, pre-mf, stretched $\mathrm{mf}$ and deformed embryos). There was a statistically significant increase in the number of deformed embryos in the THP group $(p<0.05)$ and 06 group $(p<0.001)$ compared to the vehicle group (Supporting Information Table S2). Data are presented as the mean \pm SEM. $\ddagger$ Only one female worm was recovered from all the animals treated with $1 \mathrm{mg} / \mathrm{kg}$ PVP; therefore, no analyses of overnight $\mathrm{mf}$ shed nor embryograms were conducted.
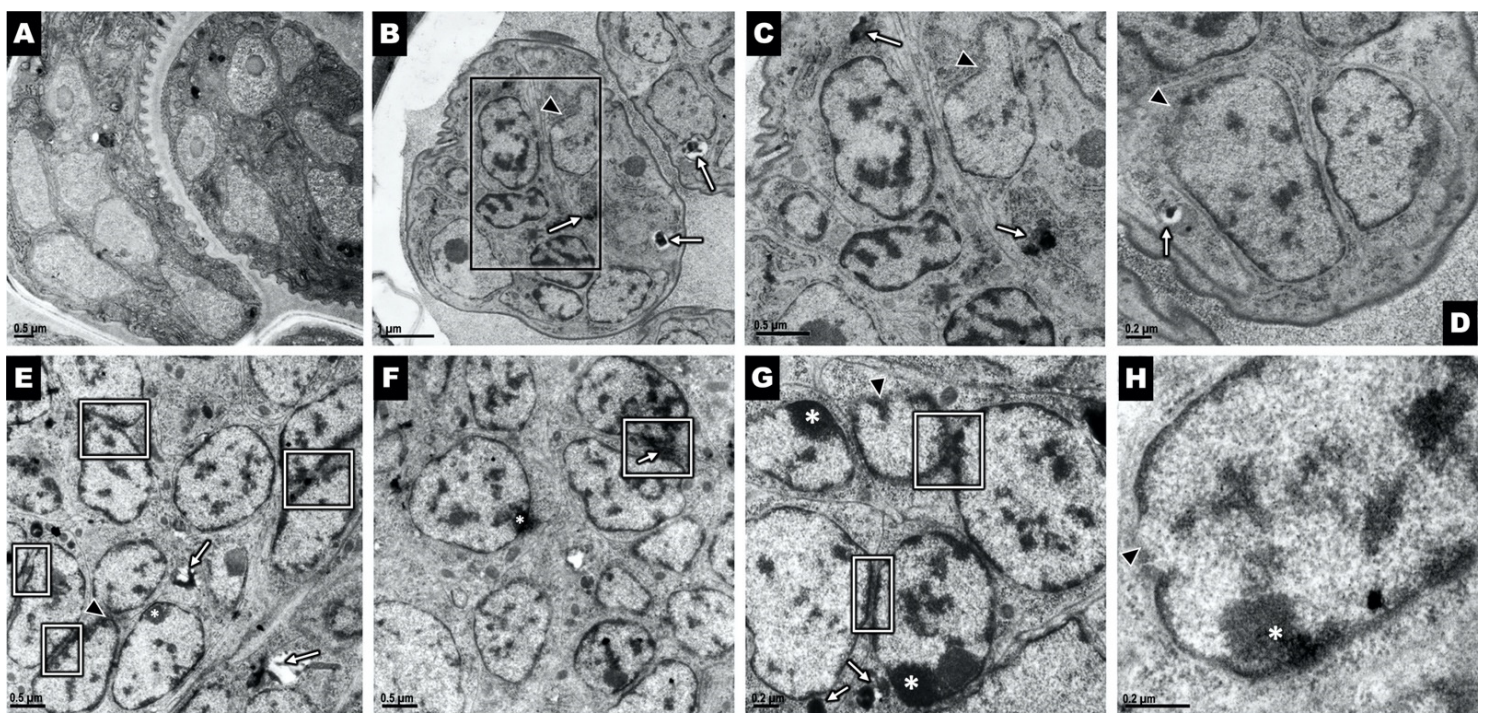

Figure 5. Ultrastructural analysis shows sub-cellular abnormalities in the gonads of the THP- and analog 06-treated worms. (A) Microphotograph of a female gonad from a control animal treated with vehicle alone. Cellular inclusions are rare and all nuclear envelopes appear intact. Images (B-D) are representative images of developing microfilariae inside the reproductive structures of female worms removed from animals treated with THP. The black arrowheads show disrupted nuclear envelopes while white arrows point to internal cellular aggregates. The black box in image B delineates the region seen at a higher magnification in image $(\mathbf{C})$. Images $(\mathbf{E}-\mathbf{H})$ are representative images of developing microfilariae inside the gonad of female worms removed from animals treated with analog 06. The white boxes show nuclear membranes that are closely juxtaposed with one another, an unusual feature that may be due to the disruption of the main cellular membrane. White arrows point to aggregates within the cellular structures, which frequently occur at the surface of the nuclear envelope. Arrowheads point to disruption of the nuclear envelope which appears more advanced in worms treated with 06 compared to those treated with THP. The asterisks indicate abnormal accumulation of heterochromatin at the internal surface of the nuclear envelope. 


\section{Discussion}

Currently, there is no anti-filarial drug that directly targets adult worms nor is there a vaccine available that prevents filarial infection. One strategy to reduce the cost of drug-discovery efforts and accelerate the development of new therapies to treat neglected parasitic diseases is to evaluate repurposed drugs, i.e., those that have already been tested and found to be safe in humans for other indications.

Pyrvinium pamoate (PVP) is an anthelmintic originally used to treat pinworm infections (enterobiasis, oxyuriasis) and strongyloidiasis [16-18]. It has also been used in combination with thiabendazole to treat children infected with the parasitic worms Trichuris trichiura and Ascaris lumbricoides [19]. PVP is also efficacious as an anti-protozoal drug against Cryptosporidium parvum [20], Entamoeba histolytica [21], Giardia intestinalis [21] and Plasmodium falciparum [22], and it has been shown to suppress the growth of pathogenic yeast such as Exophiala dermatitidis [23] and Candida albicans strain i(5L) [24].

To identify repurposed drugs for use as anti-filarial agents, we first screened a library of FDA-approved drugs with adult $B$. pahangi in vitro and found that PVP was the most potent compound among the 2200 that were tested; it reduced motility of $B$. pahangi with an $\mathrm{IC}_{50}$ in the sub-nanomolar range $(0.3 \mathrm{nM})$ [11]. This study extends the initial observation as well as presents the comparative outcomes of testing PVP and several of its analogs on Brugia and other filarial parasites. We found that these compounds were highly potent in vitro against filarial worms across species and life stages, with $\mathrm{IC}_{50} \mathrm{~s}$ in the sub-micromolar range for all worm types tested.

We also observed that PVP, THP and analog 06 were not only potent against the adult worms but they were also potent in preventing the molting of the infectious stage of O. volvulus (L3, third-stage larvae). Due to the high cost of distribution of microfilaricides such as ivermectin, mass drug distribution is not implemented in hypo-endemic areas (low prevalence of infections) in Africa, which possibly contributes to continued transmission through human migrations, consequently reintroducing the parasite back into regions where it might have once been controlled [8]. Thus, PVP and its analogs, which may also prevent the infectious L3 from further development during newly acquired infections, show promise as chemoprophylactic drugs [25] as well as potential macrofilaricidal drugs.

Currently, there are test and treat programs in areas co-endemic for onchocerciasis and loaiasis where ivermectin can still be administered through MDA [26]. Epidemiological and modelling studies, however, have indicated that annual ivermectin MDA may not be sufficient to lead to elimination of transmission in previously hyperendemic and holoendemic foci. Moreover, some of the macrofilaricidal candidate drugs in clinical trials performed by DNDi [27] also have some effect on $\mathrm{mf}$ but this does not detract from testing them due to the urgent need to identify new macrofilaricidal drugs that can support elimination.

To assess the potential use of PVP, THP and 06 in countries co-endemic for Loa loa, further in vitro studies are necessary to determine the $\mathrm{IC}_{50} \mathrm{~s}$ of these compounds with $\mathrm{mf}$, as well as validating the potency of these compounds on the $\mathrm{mf}$ in animal models [28]. In the present study, in vitro assays were conducted at single concentrations $(10 \mu \mathrm{M})$ in which PVP, THP and 06 inhibited motility of $\mathrm{mf}$ by $100 \%, 100 \%$ and $88 \%$, respectively. The $\mathrm{IC}_{50}$ of PVP with $O$. ochengi $\mathrm{mf}$ was 3 - and 6-fold higher than the $\mathrm{IC}_{50} \mathrm{~s}$ for adult male and female $O$. ochengi, respectively, which suggests that PVP may not be as potent on the microfilarial stage, and thus bodes well for its possible use as a macrofilaricidal drug in countries endemic for both onchocerciasis and loaiasis.

PVP, THP and analog 06 were also assessed in the B. pahangi-gerbil model of infection. The PVP group had a 95\% decrease in worm burden and a 100-fold reduction in the number of microfilariae compared to the vehicle group. Although this was not statistically significant due to high variance, results showed that female worm fecundity was clearly reduced in both the THP and 06 groups. Embryogram analyses showed that both THP and 06 impacted embryogenesis and the reproductive output of the female worms. Moreover, they caused an increase in the number of deformed embryos and a reduction in the number of $\mathrm{mf}$ shed overnight compared to the controls. Because transmission of filariasis and the 
clinical pathology of river blindness is driven by $\mathrm{mf}$, a macrofilaricidal drug that confers long-term sterility of female worms is also viewed as a viable therapeutic approach [29].

Interestingly, the levels of the endosymbiont, Wolbachia, were not reduced in any treatment group, suggesting that the effects of the compounds on embryogenesis and fecundity are not mediated through the host-endosymbiont interaction as seen with antibiotics such as doxycycline and rifampicin [29-39], but probably by acting directly on yet unknown targets within the worms that are essential for embryogenesis.

The underlying mechanisms by which PVP, THP and 06 affect adult and larval filarial worms are unknown. In addition to its other anti-parasitic activities, studies have shown that PVP inhibits the proliferation of tumor cells across a range of in vitro and in vivo models of various types of cancers, including colon, breast, lung, prostate, pancreatic cancer, myeloma and lymphoma and has also shown potential as an anti-tuberculosis agent $[13,40-43]$. Potential targets of PVP include the Wnt signaling pathway, the Hedgehog pathway, androgen receptors, mitochondrial respiration and glycolysis and further study is needed to determine if PVP and its analogs target similar pathways in filarial worms. It is possible that the application of these compounds, may not only be limited to filarial worm infections but also against other diseases, thus adding value to these new analogs that were synthesized based on the PVP scaffold.

\section{Materials and Methods}

\subsection{Ethics Statement}

All animal experiments were carried out under protocols approved by the University of California, San Francisco Institutional Animal Care and Use Committee (IACUC), approval number AN173847-02, and adhered to the guidelines set forth in the NIH Guide for the Care and Use of Laboratory Animals and the USDA Animal Care Policies.

\subsection{Synthesis of Pyrvinium Pamoate Analogs}

Tetrahydropyrvinium (THP, 2-[2-(2,5-dimethyl-1-phenylpyrrol-3-yl)ethenyl]-N,N,1trimethyl-2H-quinolin-6-amine) was synthesized as described in US Patent 8,580,773 [15]. Briefly, pyrvinium pamoate ( $456 \mathrm{mg}, 0.4 \mathrm{mmol}, 1.0$ equiv.) was purchased from US Pharmacopeia (catalog \# 1592001) and suspended in ethanol (9 mL), in a $20 \mathrm{~mL}$ vial. The mixture was stirred at room temperature under air and sodium borohydride $(76 \mathrm{mg}, 2.0 \mathrm{mmol}$, 5.1 equiv.) was added. The vial was capped and the reaction mixture was stirred for $4.5 \mathrm{~h}$, after which time water $(2 \mathrm{~mL})$ was added and the resulting suspension was poured into a $25 \mathrm{~mL}$ separatory funnel and extracted 3 times with $7 \mathrm{~mL}$ dichloromethane. The combined organic layer was dried with sodium sulfate, filtered and concentrated. The residue was purified using automated silica gel chromatography on a $12 \mathrm{~g}$ Silicycle cartridge that had been preequilibrated with hexane (Hex) then in a gradient of $0-25 \%$ ethyl acetate (EA) in Hex and then $25 \%$ EA/Hex. The relevant fractions were collected and concentrated to afford tetrahydropyrvinium (116 mg, 32.2\%).

${ }^{1} \mathrm{H}$ NMR $(300 \mathrm{MHz}$, chloroform-d) $\delta \mathrm{ppm} 1.51-1.82(\mathrm{~m}, 1 \mathrm{H}), 1.86-2.27(\mathrm{~m}, 9 \mathrm{H})$, 2.61-3.09 (m, 11H), 3.78 (brs., $1 \mathrm{H}), 5.87(\mathrm{dd}, \mathrm{J}=15.6,7.9 \mathrm{~Hz}, 1 \mathrm{H}), 6.18(\mathrm{~s}, 1 \mathrm{H}), 6.45$ $(\mathrm{d}, \mathrm{J}=15.6 \mathrm{~Hz}, 1 \mathrm{H}), 6.63(\mathrm{~d}, \mathrm{~J}=7.9 \mathrm{~Hz}, 2 \mathrm{H}), 6.68-6.76(\mathrm{~m}, 1 \mathrm{H}), 7.14-7.24(\mathrm{~m}, 2 \mathrm{H}), 7.36-7.54$ (m, 3H). ${ }^{13} \mathrm{C}$ NMR (100 MHz, chloroform-d) $\delta$ ppm 10.7, 12.7, 25.5, 29.3, 37.5, 42.5, 62.4, $103.1,112.1,113.9,116.1,117.5,123.1,124.0,125.8,127.0,127.8,128.2,129.1,129.6,138.5$, 139.4, 142.7.

LC-MS (ESI) $m / z 386.5(\mathrm{M}+\mathrm{H})^{+}$.

Analogs 01 (2-[(E)-2-(2,5-dimethyl-1-phenyl-1H-pyrrol-3-yl)ethenyl]-1-methylquinolin1-ium iodide), 02 (2-[(E)-2-(2,5-dimethyl-1-phenyl-1H-pyrrol-3-yl)ethenyl]-1,6-dimethylquin olin-1-ium iodide), 04 (1-methyl-2-[(E)-2-(1-phenyl-1H-pyrazol-4-yl)ethenyl]quinolin-1-ium iodide) and 05 (2-[(E)-2-(3,5-dimethyl-1-phenyl-1H-pyrazol-4-yl)ethenyl]-1-methylquinolin1-ium iodide) were kindly provided by Dr. Marc Diamond. Analog 03 (1-methyl-2-[(E)-2(5-methyl-1-phenyl-1H-pyrazol-4-yl)ethenyl]quinolin-1-ium iodide) (Figure 6A) was synthesized as follows. 5-methyl-1-phenyl-1H-pyrazole-4-carbaldehyde (196 mg, $1.05 \mathrm{mmol})$ 
and 1,2-dimethylquinolin-1-ium iodide (250 $\mathrm{mg}, 0.877 \mathrm{mmol})$ were dissolved and stirred in dry methanol $(5 \mathrm{~mL})$ in a septum-capped vial and then purged with dry argon. Piperidine $(0.104 \mathrm{~mL}, 1.05 \mathrm{mmol})$ was added with a syringe and the reaction was stirred in an aluminum heating block at $60{ }^{\circ} \mathrm{C}$ for $4 \mathrm{~h}$, until the reaction was complete as judged by LC-MS. Solvent was removed with a rotary evaporator, and the residue was re-suspended in $12 \mathrm{~mL}$ 2:1 (v:v) diethyl ether:methanol and filtered on paper. The filter cake was washed with an additional $6 \mathrm{~mL}$ portion of the 2:1 mixture, then diethyl ether, $6 \mathrm{~mL}$. The product was dried in air under foil to protect it from light for $18 \mathrm{~h}$ to afford the product $(264 \mathrm{mg}, 66.4 \%)$.<smiles>Cc1c(C=O)cnn1-c1ccccc1</smiles><smiles>Cc1ccc2ccccc2[n+]1C</smiles><smiles></smiles>

(A)<smiles>Cc1nn(-c2ccccc2)c(C)c1C=O</smiles>

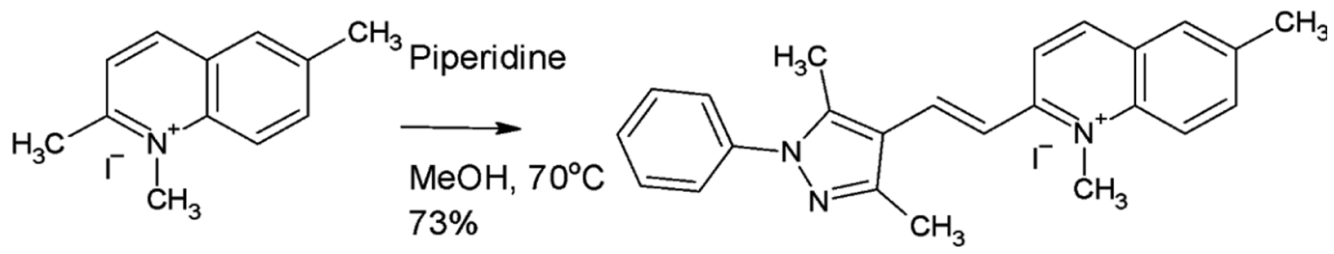

(B)

Figure 6. (A) Synthesis of analog 03. (B) Synthesis of analog 06.

${ }^{1} \mathrm{H}$ NMR (400 MHz, DMSO-d6) $\delta$ ppm 2.44-2.56 (m, 3H), $4.44(\mathrm{~s}, 3 \mathrm{H}), 7.42(\mathrm{td}$, $\mathrm{J}=5.8,2.6 \mathrm{~Hz}, 1 \mathrm{H}), 7.46-7.55(\mathrm{~m}, 4 \mathrm{H}), 7.61(\mathrm{~d}, \mathrm{~J}=15.6 \mathrm{~Hz}, 1 \mathrm{H}), 7.82(\mathrm{t}, \mathrm{J}=7.6 \mathrm{~Hz}, 1 \mathrm{H})$, $8.05(\mathrm{t}, \mathrm{J}=7.5 \mathrm{~Hz}, 1 \mathrm{H}), 8.14(\mathrm{~d}, \mathrm{~J}=15.3 \mathrm{~Hz}, 1 \mathrm{H}), 8.23(\mathrm{~d}, \mathrm{~J}=7.7 \mathrm{~Hz}, 1 \mathrm{H}), 8.43(\mathrm{~d}, \mathrm{~J}=9.0 \mathrm{~Hz}$, $1 \mathrm{H}), 8.54(\mathrm{~s}, 1 \mathrm{H}), 8.64(\mathrm{~d}, \mathrm{~J}=9.3 \mathrm{~Hz}, 1 \mathrm{H}), 8.89(\mathrm{~d}, \mathrm{~J}=9.0 \mathrm{~Hz}, 1 \mathrm{H}) .{ }^{13} \mathrm{C} \mathrm{NMR}(100 \mathrm{MHz}$, DMSO-d6) $\delta$ ppm 10.8, 39.6, 115.6, 118.8, 119.2, 120.6, 124.8, 127.3, 128.4, 128.5, 129.3, 129.9, $134.5,138.6,138.6,139.1,139.7,141.9,142.9,156.2$

LC-MS (ESI) $m / z 326.03(\mathrm{M})^{+}$.

Analog 06 (2-[(E)-2-(3,5-dimethyl-1-phenyl-1H-pyrazol-4-yl)ethenyl]-1,6-dimethylquin olin-1-ium iodide) (Figure 6B) was synthesized using 3,5-dimethyl-1-phenyl-1H-pyrazole4-carbaldehyde (175 mg, $0.877 \mathrm{mmol}$ ) and 1,2,6-trimethylquinolin-1-ium iodide (250 mg, $0.836 \mathrm{mmol})$ that were dissolved and stirred in dry methanol $(5 \mathrm{~mL})$ in a septum-capped vial and then purged with dry argon. Piperidine $(0.120 \mathrm{~mL}, 1.22 \mathrm{mmol})$ was added with a syringe and the reaction was stirred in an aluminum heating block at $70^{\circ} \mathrm{C}$ for $4 \mathrm{~h}$, until the reaction was complete as judged by LC-MS. Solvent was removed with a rotary evaporator, and the residue was re-suspended in $12 \mathrm{~mL}$ 2:1 (v:v) diethyl ether:methanol and filtered on paper. The filter cake was washed with an additional $6 \mathrm{~mL}$ portion of the 2:1 mixture, then $6 \mathrm{~mL}$ diethyl ether. The product was dried in air under foil to protect from light for $18 \mathrm{~h}$ to afford the product (293 $\mathrm{mg}, 72.8 \%$ ).

${ }^{1} \mathrm{H}$ NMR (400 MHz, DMSO-d6) $\delta$ ppm $8.89(\mathrm{~d}, \mathrm{~J}=9.0 \mathrm{~Hz}, 1 \mathrm{H}), 8.64(\mathrm{~d}, \mathrm{~J}=9.3 \mathrm{~Hz}$, $1 \mathrm{H}), 8.45(\mathrm{~d}, \mathrm{~J}=9.3 \mathrm{~Hz}, 1 \mathrm{H}), 8.06-8.15(\mathrm{~m}, 2 \mathrm{H}), 8.01(\mathrm{dd}, \mathrm{J}=9.3,2.0 \mathrm{~Hz}, 1 \mathrm{H}), 7.53-7.62$ $(\mathrm{m}, 4 \mathrm{H}), 7.51(\mathrm{dd}, \mathrm{J}=6.1,2.4 \mathrm{~Hz}, 1 \mathrm{H}), 7.26(\mathrm{~d}, \mathrm{~J}=16.1 \mathrm{~Hz}, 1 \mathrm{H}), 4.49(\mathrm{~s}, 3 \mathrm{H}), 2.54-2.62(\mathrm{~m}, 9 \mathrm{H})$. ${ }^{13} \mathrm{C}$ NMR (100 MHz, DMSO-d6) $\delta$ ppm 11.5, 14.1, 20.6, 39.5, 39.6, 115.4, 116.0, 119.0, 120.7, $124.9,127.4,128.3,128.8,129.3,136.4,137.5,138.3,138.4,138.8,142.5,142.6,149.0,155.6$.

LC-MS (ESI) $m / z 354.07(\mathrm{M})^{+}$. 


\subsection{In Vitro Motility Assays with Adult Female Brugia pahangi}

A series of in vitro assays were conducted to test the activity of pyrvinium pamoate (PVP), tetrahydropyrvinium (THP), and 6 additional PVP derivatives (01, 02, 03, 04,05 and 06) with adult female B. pahangi, adult and $\mathrm{mf}$ of Onchocerca ochengi, O. volvulus L3 and L5 pre-adults, and Loa loa $\mathrm{mf}$. Compounds were initially screened against B. pahangi adult females for 3 days in a motility-based assay as previously described [44,45]. Briefly, individual B. pahangi females were plated into each well of a 24-well plate containing $0.5 \mathrm{~mL}$ Brugia culture media (RPMI-1640 with $25 \mathrm{mM}$ HEPES, $2.0 \mathrm{~g} / \mathrm{L} \mathrm{NaHCO}_{3}, 5 \%$ heat inactivated fetal bovine serum (FBS), and $1 \times$ Antibiotic/Antimycotic solution), then treated with $1 \mu \mathrm{M}$ compound; media containing $1 \%$ DMSO was used as negative controls. Worms were kept in a $37{ }^{\circ} \mathrm{C}$ incubator with $5 \% \mathrm{CO}_{2}$. Motility was monitored daily using the Worminator system [44] and percent inhibition was calculated as compared to the mean movement units (MMUs) of $1 \%$ DMSO controls. Compounds that reduced worm motility by $70 \%$ or greater were tested using a 6-point serial dilution of compound (ranging from 30 to $1 \times 10^{-5} \mu \mathrm{M}$ ), and $\mathrm{IC}_{50}$ s were calculated using GraphPad Prism software.

\subsection{In Vitro Assays with Adult Onchocerca ochengi and Mf and Loa loa Mf}

As humans are the only hosts for $O$. volvulus which are unavailable for screening, drug discovery relies on the surrogate filarial parasites Brugia spp. and cattle Onchocerca spp. Prioritized compounds from the Brugia worm screens were further tested with female and male adult $O$. ochengi as well as $O$. ochengi and $L . l o a ~ m f . ~ \mathrm{IC}_{50}$ s were calculated for assays performed with female and male adults for all compounds except for 04 and 05 , which were assayed with $O$. ochengi males at $10 \mu \mathrm{M}$ only.

For these assays, O. ochengi adults were extracted from the subcutaneous nodules of infected cow skins purchased from the local slaughterhouse (Douala, Littoral Region, Cameroon) and incubated in $4 \mathrm{~mL}$ complete culture media comprised of RPMI-1640 (SigmaAldrich), $5 \%$ newborn calf serum, 200 units $/ \mathrm{mL}$ penicillin, $200 \mu \mathrm{g} / \mathrm{mL}$ streptomycin and $2.5 \mu \mathrm{g} / \mathrm{mL}$ amphotericin B (Sigma-Aldrich) in 12-well plates overnight to validate sterility prior to the assays [44]. Four to eight $O$. ocheng $i$ adult masses were treated individually the following day with a serial dilution of each compound, and controls were treated with $1 \%$ DMSO. While in culture, the male worms normally egress from the nodules into the surrounding media and thus can be monitored in parallel for motility. The O. ochengi adult masses were incubated at $37^{\circ} \mathrm{C}$ with $5 \% \mathrm{CO}_{2}$ for the duration of the assay. Male motility within each well was visually scored every day and over 5 days after compound addition, and female viability within the nodules was assessed by MTT after 7 days as previously described [44]. The O. ochengi adult masses containing female worms were individually placed in wells of a 48-well plate with $0.5 \mathrm{~mL}$ of $0.5 \mathrm{mg} / \mathrm{mL}$ MTT in PBS and incubated at $37^{\circ} \mathrm{C}$ for $30 \mathrm{~min}$. Female viability was visually rated by the degree of formazan production (live worms have blue coloration) in the female worm within the treated nodule versus control worm masses. To calculate the $\mathrm{IC}_{50}$, quadruplicate worm masses were incubated with final concentrations of 30,10,3,1, 0.3, 0.1 and $0.03 \mu \mathrm{M}$ and assays were conducted as described above. Prism 4.0 for Windows was used to calculate $\mathrm{IC}_{50} \mathrm{~s}$.

To assess the effects of the compounds on $O$. ochengi $\mathrm{mf}$, the $\mathrm{mf}$ were harvested from infected cow skin and cultured (10-15 mf per well) in $100 \mu \mathrm{L}$ media in 96-well plates with a confluent feeder layer of monkey kidney epithelial cells (MK2) as previously described [44]. The motility was visually assessed every day and scored on a scale from $0-100 \%$ inhibition of motility after 5 days of treatment. $\mathrm{IC}_{50}$ for PVP was calculated using GraphPad Prism software. All compounds were also counter-screened with L. loa $\mathrm{mf}$ collected from infected individuals with approval from the University of Buea (IRB approval \# 964-19). Mf were separated from blood cells using a Percoll gradient as previously described [44] and set up for assays (10-15 mf per well). Treated (10 $\mu \mathrm{M}$ of compound) $\mathrm{mf}$ were incubated at $37^{\circ} \mathrm{C}$ and $5 \% \mathrm{CO}_{2}$, and the motility was visually assessed every day and finally scored for $0-100 \%$ inhibition of motility after 5 days of treatment. 


\subsection{Onchocerca volvulus Molting Assay of Third-Stage Larvae (L3) to Fourth-Stage Larvae (L4)}

O. volvulus, like other nematodes, undergo molts during their larval stages as they develop into the adult form. If the larval worms do not undergo the molt and their outer cuticle is partially or not shed, they will not survive. The molting assay tests the potency of compounds to prevent the L3 from molting to the L4 stage in vitro. PVP, THP and analogs 03 and 06 were tested in an O. volvulus L3 molting assay as previously described [44]. Briefly, 5-10 Ov L3 collected from infected Simulium blackflies and frozen in liquid nitrogen were thawed and plated in 96-well plates seeded with $0.2 \times 10^{6}$ normal human peripheral blood mononuclear cells (PBMCs) in $100 \mu \mathrm{L}$ complete medium containing $20 \%$ heat inactivated FBS and treated with compounds at 10, 3, 1, 0.3, 0.1 and $0.03 \mu \mathrm{M}$. L3 exposed to $0.5 \%$ DMSO or complete media only were run as negative controls. Larvae were incubated at $37{ }^{\circ} \mathrm{C}$ with $5 \% \mathrm{CO}_{2}$, and molting was determined by examining the wells for highly motile L4 larvae and empty L3 casts after 6 days in culture. Inhibition of molting was calculated relative to DMSO controls, and $\mathrm{IC}_{50}$ s were calculated using GraphPad Prism software.

\subsection{Onchocerca volvulus Pre-Adult (Ov L5) Assay}

O. volvulus adult male and female worms, which can only be obtained from infected individuals, are not readily accessible for ex vivo studies. Moreover, since there is no small animal model that can maintain infections by O. volvulus, a recently developed in vitro system was used to evaluate the macrofilaricidal effects on pre-adult worms [45]. All compounds except for 04 were tested in this $O$. volvulus pre-adult/L5 motility and viability assay.

Briefly, Ov L3 larvae were cultured to the pre-adult/L5 stage in vitro as described by Voronin et al., 2019 [45]. Once larvae reached the L5 stage (after at least 70 days in culture), $8-10$ Ov L 5 were moved to new transwell inserts in a 24-well plate containing $0.5 \mathrm{~mL}$ Ov L4CMS media seeded with a $3 \times 10^{4} /$ well Human Umbilical Vein Endothelial Cells (HUVEC) monolayer. Duplicate wells were treated with 1 and/or $10 \mu \mathrm{M}$ of compound. Ov L5 were exposed to compounds for 14 days (exchanged $50 \%$ of media with fresh compound every two days) and then cultured with new media without compound, exchanging $50 \%$ of media every $2-3$ days, up to day 36 . Control Ov L 5 were treated with $0.05 \%$ DMSO. Concentrations were chosen based on activity in the B. pahangi female motility assay. Motility was assessed visually and ranked on a $0-100 \%$ scale every $2-3$ days over the course of the assay. At the end of the motility assay, Ov L5 viability was measured by 3-(4,5-dimethylthiazol-2-yl)-2,5diphenyltetrazolium bromide (MTT) assay. Ov L5 were incubated with $0.1 \%$ MTT in PBS at $37^{\circ} \mathrm{C}$ for $1 \mathrm{~h}$ then visually inspected for blue coloration indicating MTT reduction. Worms were considered dead if $<50 \%$ of the worm was stained blue, and worms were considered alive if $>50 \%$ of the worm was stained blue.

\subsection{In Vitro Absorption, Distribution, Metabolism and Excretion (ADME)}

In vitro gerbil liver microsome assays and MDCK permeability assays were conducted by Quintara Biosciences (South San Francisco, CA) with PVP, THP, 01, 02, 03, 05 and 06 to determine the stability and permeability of each compound. Microsomal stability was tested using $1 \mu \mathrm{M}$ of each test compound in a 96-well plate containing $0.5 \mathrm{mg} / \mathrm{mL}$ gerbil liver microsomes, $1 \mathrm{mM}$ NADPH and/or UDPGA with alamethicin in a buffer of $100 \mathrm{mM}$ potassium phosphate with $3 \mathrm{mM}$ magnesium chloride at $\mathrm{pH}$ 7.4. Verapamil was used as a positive control. Reactions were incubated at $37^{\circ} \mathrm{C}$, and $100 \%$ acetonitrile with $0.1 \%$ formic acid was added at $0,15,30$ and $60 \mathrm{~min}$ timepoints to stop the reaction. Samples were then separated over a Waters Atlantis T3 dC18 reverse phase HPLC column with $0.1 \%$ formic acid in water and $0.1 \%$ formic acid in acetonitrile. Samples were analyzed using an $A B$ Sciex API 4000 LC-MS/MS.

Permeability assays were conducted using $5 \mu \mathrm{M}$ of each test compound with digoxin as a control. Compounds were added to the apical and basal sides of wells with a confluent layer of MDCK-MDR1 cells that had been pre-washed in Hank's Balanced Salt Solution with $5 \mathrm{mM}$ HEPES. Transendothelial electrical resistance was used to verify the integrity 
of the MDCK-MDR1 monolayer. After compound addition, plates were incubated at $37{ }^{\circ} \mathrm{C}$ with $5 \% \mathrm{CO}_{2}$ for $1 \mathrm{~h}$. Samples were analyzed by LC-MS/MS and net flux ratio was calculated using basal-to-apical and apical-to-basal permeability.

\subsection{In Vivo Studies with the Brugia pahangi/Gerbil Model of Infection}

Male Mongolian gerbils 50-60 g, 5-7 weeks in age (Meriones unguiculatus, Charles River Laboratories International, Inc., Wilmington, MA, USA) were injected intraperitoneally (IP) with 200 third-larval stage B. pahangi and treated a minimum of 3 months later when larvae developed into adult worms [46].

PVP, THP, and 06 were dissolved in DMSO $(20 \mathrm{mg} / \mathrm{mL})$ and the stock was added to $44 \%$ beta-hydroxypropylcyclodextrin (20\% solution) and 55\% PEG400 for a final compound concentration of $0.2 \mathrm{mg} / \mathrm{mL}$ in 1\% DMSO. Animals were given IP doses of $1 \mathrm{mg} / \mathrm{kg}$ once a day for 5 days based on in vivo studies by Jones et al., 2009 [14] and gerbil PK analyses. Compounds are light sensitive and were shielded from light during formulation. Animals were necropsied 13 weeks post-first dose, and peritoneal cavities were washed with $100 \mathrm{~mL}$ of PBS to collect adult worms and $\mathrm{mf}$ that had been released from female worms. Adult worms were separated by sex, counted, and processed for subsequent analyses. Mf from the peritoneal cavities were quantified by mixing peritoneal wash 9:1 (v/v) with 0.04\% methylene blue:water and counted using an inverted microscope.

\subsection{Ex Vivo Microfilarial Release by Female Brugia pahangi Worms and Embryograms}

To test the effects of the compounds on female worm fertility, all surviving female worms were examined ex vivo to quantify the amount of $\mathrm{mf}$ released and profile the various stages of embryonic development within the uteri of individual female worms. After necropsy, female worms were incubated in individual wells of a 24-well plate with $2 \mathrm{~mL}$ Brugia culture media at $37^{\circ} \mathrm{C}$ and $5 \% \mathrm{CO}_{2}$. After $24 \mathrm{~h}$, the number of $\mathrm{mf}$ released by each adult female was determined by counting the $\mathrm{mf}$ in a $0.5 \mathrm{~mL}$ sample of the media and multiplying by 4 to calculate the total number of mf. Additionally, embryogram analyses on the individual female worms was performed as described [46]. Briefly, each female worm was homogenized in $500 \mu \mathrm{L}$ of PBS to release the uterine content. The embryonic developmental stages (eggs, embryos, pre-mf and $\mathrm{mf}$ ) were determined in two $10 \mu \mathrm{L}$ aliquots using a compound microscope and hemocytometer. A minimum of 200 events were assessed from each female worm and at least 3 females were analyzed per animal from at least 3 animals per treatment group. The intra-uterine embryogram was expressed as the relative proportions of different stages of development: eggs, embryos, pre-mf, stretched $\mathrm{mf}$ and deformed embryos in the total number of events.

\subsection{0. qPCR of Wolbachia and Worm DNA in Treated Female Worms}

During necropsy, adult worms were collected and frozen in a dry-ice and ethanol bath, then stored at $-80{ }^{\circ} \mathrm{C}$. Genomic DNA was extracted using a DNEasy Blood and Tissue Kit (QIAGEN). Female worms were processed individually, and male worms were pooled in groups of 4 per sample for processing. DNA was quantified using a NanoDrop One $^{c}$ (Thermo Fisher Scientific) before conducting qPCR with Genecoepia $2 \times$ All-in-One Master Mix (Cat \#QP001-01) in a Bio-Rad CFX Connect RT-PCR thermocycler. The single copy genes, Wolbachia surface protein (wsp) and Brugia glutathione S-transferase (gst), were used to calculate wsp:gst ratios to normalize Wolbachia titers to Brugia DNA as previously described [46]. The following primers were used to amplify wsp, wsp_fwd $5^{\prime}$ CCCTGCAAAGGCACAAGTTATTG-3'; wsp_rev 5'-CGAGCTCCAGCAAAGAGTTTAATTT$3^{\prime}$ with the following amplification cycles: heating at $95{ }^{\circ} \mathrm{C}$ for $15 \mathrm{~min}$, followed by 40 cycles of denaturation at $94{ }^{\circ} \mathrm{C}$ for $10 \mathrm{~s}$, annealing at $55{ }^{\circ} \mathrm{C}$ for $20 \mathrm{~s}$ and elongation at $72{ }^{\circ} \mathrm{C}$ for $15 \mathrm{~s}$. The following primers were used to amplify gst, gst_fwd $5^{\prime}$ GAGACACCTTGCTCGCAAAC-3'; ${ }^{\prime}$ st_rev $5^{\prime}$-ATCACGGACGCCTTCACAG-3' with the following amplification cycles: heating at $95{ }^{\circ} \mathrm{C}$ for $15 \mathrm{~min}$, followed by 36 cycles of 
denaturation at $94{ }^{\circ} \mathrm{C}$ for $15 \mathrm{~s}$, annealing at $55^{\circ} \mathrm{C}$ for $30 \mathrm{~s}$ and elongation at $72{ }^{\circ} \mathrm{C}$ for $30 \mathrm{~s}$ [46].

\subsection{Statistical Analysis of the In Vivo Study}

Worm burden, peritoneal $\mathrm{mf}$ counts, overnight $\mathrm{mf}$ sheds and $\mathrm{qPCR}$ data were analyzed using a Kruskal-Wallis test followed by Dunn's multiple comparison. To determine significant differences in embryograms, a two-way ANOVA was conducted with a Dunnett's multiple comparisons test, and significance levels were determined based on comparisons with vehicle treated animals. All statistical analyses were determined using Prism 8 version $8.2 .0(272)$.

\subsection{Transmission Electron Microscopy of Ov L5 (In Vitro) and Brugia pahangi Adult Females (In Vivo)}

Ov L5 treated with $10 \mu \mathrm{M}$ THP in vitro for 21 days and untreated worms were prepared for ultrastructural analysis by transmission electron microscopy (TEM) as previously described [46]. Briefly, worms were fixed in $2.5 \%$ glutaraldehyde and $2 \%$ paraformaldehyde in $0.1 \mathrm{M}$ sodium cacodylate buffer and then stored at $4{ }^{\circ} \mathrm{C}$. Fixed worms were washed 3 times in the buffer only and then post-fixed in $2 \%$ osmium tetroxide for $1 \mathrm{~h}$ and washed 3 times in buffer again. The fixed worms were dehydrated by immersion in an ethanol series, infiltrated with propylene oxide, embedded in epon 812 resin, and then incubated in an oven at $60{ }^{\circ} \mathrm{C}$ for $48 \mathrm{~h}$ to polymerize. An RMC MTX ultramicrotome with a Diatome diamond knife was used to cut ultrathin sections, which were stained using Uranyless (EMS, USA) and Reynold's lead citrate. Images of samples were obtained using a FEI Tecnai 12 Spirit transmission electron microscope at $80 \mathrm{kV}$.

B. pahangi adult females recovered from gerbils treated with $1 \mathrm{mg} / \mathrm{kg}$ THP and analog 06 were prepared as above except worms were cut into approximately $5 \mathrm{~mm}$ long pieces taken from the center of the worm. Pieces were washed for one hour in $0.1 \mathrm{M}$ sodium cacodylate followed by post-fixation in 1\% osmium tetroxide for $1 \mathrm{~h}$ and again washed in the same buffer for another hour. Sample pieces were dehydrated using an increasing concentration of ethanol and resin (Durcupan, by Fluka) and transitioned using propylene oxide. Samples were left overnight in pure resin at $4{ }^{\circ} \mathrm{C}$. Samples pieces were embedded using Beem capsules (Electron Microscopy Sciences) and cured at $60{ }^{\circ} \mathrm{C}$ overnight. All reagents were purchased from Electron Microscopy Sciences.

Blocks were trimmed and sectioned using a diamond knife on a Sorvall MT-6000 ultramicrotome, collected on formvar coated $1 \mathrm{~mm}$ slot grids and contrasted using uranyl acetate and lead citrate. Grids were imaged on a Philips CM100 transmission electron microscope at $80 \mathrm{kV}$ and images were collected using a Gatan Orius imaging system.

\section{Conclusions}

PVP and its two analogs, THP and 06, were highly potent against filarial worms across life history stages and species in in vitro worm assays with $\mathrm{IC}_{50} \mathrm{~s}$ in the sub-nanomolar to sub-micromolar range. These compounds impaired female worm fecundity and embryogenesis in in vivo studies. Because transmission of filariasis and the clinical pathology of river blindness are driven by the presence of microfilariae in the human host, a macrofilaricidal drug that confers long-term sterility of female worms is also viewed as a viable therapeutic approach. PVP, THP and 06 were also potent in preventing the molting of Onchocerca volvulus infective third-stage larvae, which also positions them for potential use as chemoprophylactic drugs in preventing larvae from developing into the adult stages. In conclusion, PVP and its analogs show promise as new leads for further drug development against filarial worm infections both for chemoprophylactic use and macrofilaricidal therapy. 
Supplementary Materials: The following are available online at https: / / www.mdpi.com/article/ 10.3390/ph15020189/s1, Figure S1: Molting assay; Figure S2: Wolbachia titers from female worms; Table S1: MTT assays; Table S2: Embryogram analyses.

Author Contributions: Conceptualization, A.R.R., S.L. and J.A.S.; methodology, E.L.G., C.B., C.A.B., C.F., M.L., I.V., S.J., N.T., D.V. and C.C.; analyses, E.L.G., C.A.B., C.F., K.-C.L., S.J., N.T., D.V., C.C., R.B.A., F.P.T.M. and G.E.M.; investigation, E.L.G., C.B., C.A.B., C.F., M.L., I.V., K.-C.L., S.J., N.T., D.V., C.C., R.B.A., F.P.T.M., G.E.M. and B.B.; resources, C.C., F.C.-N., B.B., A.R.R., S.L. and J.A.S.; writing-original draft preparation, E.L.G., C.A.B., C.B. and C.C.; writing-review and editing, A.R.R., S.L. and J.A.S.; supervision, D.V., C.C., F.C.-N., B.B., A.R.R., S.L. and J.A.S.; project administration, J.A.S.; funding acquisition, J.A.S.; All authors have read and agreed to the published version of the manuscript.

Funding: This work was supported by the National Institute of Allergy and Infectious Diseases of the National Institutes of Health under Award Number R21AI127639 to J.A.S.

Institutional Review Board Statement: All animal experiments were carried out under protocols approved by the University of California, San Francisco Institutional Animal Care and Use Committee (IACUC), approval number AN173847-02, and adhered to the guidelines set forth in the NIH Guide for the Care and Use of Laboratory Animals and the USDA Animal Care Policies.

Informed Consent Statement: Not applicable.

Data Availability Statement: Not applicable.

Acknowledgments: We thank Christopher Franklin, UC San Francisco, for his technical assistance.

Conflicts of Interest: The authors declare no conflict of interest. The content is solely the responsibility of the authors and does not necessarily represent the official views of the National Institutes of Health.

\section{References}

1. GBD 2017 Disease and Injury Incidence and Prevalence Collaborators. Global, Regional, and National Incidence, Prevalence, and Years Lived with Disability for 354 Diseases and Injuries for 195 Countries and Territories, 1990-2017: A Systematic Analysis for the Global Burden of Disease Study 2017. Lancet 2018, 392, 1789-1858. [CrossRef]

2. Rajasekaran, S.; Anuradha, R.; Manokaran, G.; Bethunaickan, R. An Overview of Lymphatic Filariasis Lymphedema. Lymphology 2017, 50, 164-182.

3. WHO. Global Programme to Eliminate Lymphatic Filariasis: Progress Report, 2015. Relev. Epidemiol. Hebd. 2016, 91, 441-455.

4. Hotez, P.J.; Lo, N.C. 27-Neglected Tropical Diseases: Public Health Control Programs and Mass Drug Administration. In Hunter's Tropical Medicine and Emerging Infectious Diseases, 10th ed.; Ryan, E.T., Hill, D.R., Solomon, T., Aronson, N.E., Endy, T.P., Eds.; Elsevier: London, UK, 2020; pp. 209-213. [CrossRef]

5. Gems, D. Longevity and Ageing in Parasitic and Free-Living Nematodes. Biogerontology 2000, 1, 289-307. [CrossRef]

6. Gardon, J.; Gardon-Wendel, N.; Kamgno, J.; Chippaux, J.P.; Boussinesq, M. Serious Reactions after Mass Treatment of Onchocerciasis with Ivermectin in an Area Endemic for Loa loa Infection. Lancet 1997, 350, 18-22. [CrossRef]

7. Boussinesq, M.; Gardon, J.; Gardon-Wendel, N.; Chippaux, J.-P. Clinical Picture, Epidemiology and Outcome of Loa-Associated Serious Adverse Events Related to Mass Ivermectin Treatment of Onchocerciasis in Cameroon. Filaria J. 2003, 2, S4. [CrossRef]

8. Molyneux, D.H.; Hopkins, A.; Bradley, M.H.; Kelly-Hope, L.A. Multidimensional Complexities of Filariasis Control in an Era of Large-Scale Mass Drug Administration Programmes: A Can of Worms. Parasite Vectors 2014, 7, 363. [CrossRef] [PubMed]

9. Davis, E.L.; de Vlas, S.J.; Fronterre, C.; Hollingsworth, T.D.; Kontoroupis, P.; Michael, E.; Prada, J.M.; Smith, M.E.; Stolk, W.A.; Touloupou, P. The Roadmap towards Elimination of Lymphatic Filariasis by 2030: Insights from Quantitative and Mathematical Modelling. Gates Open Res. 2019, 3, 1538. [CrossRef]

10. Basáñez, M.G.; Walker, M.; Hamley, J.I.D.; Milton, P.; Fronterre, C.; de Vlas, S.J.; Stolk, W.A. The World Health Organization 2030 Goals for Onchocerciasis: Insights and Perspectives from Mathematical Modelling. Gates Open Res. 2019, 3, 1545. [CrossRef]

11. Tyagi, R.; Bulman, C.A.; Cho-Ngwa, F.; Fischer, C.; Marcellino, C.; Arkin, M.R.; McKerrow, J.H.; McNamara, C.W.; Mahoney, M.; Tricoche, N.; et al. An Integrated Approach to Identify New Anti-Filarial Leads to Treat River Blindness, a Neglected Tropical Disease. Pathogens 2021, 10, 71. [CrossRef] [PubMed]

12. Smith, T.C.; Kinkel, A.W.; Gryczko, C.M.; Goulet, J.R. Absorption of Pyrvinium Pamoate. Clin. Pharmacol. Ther. 1976, 19, 802-806. [CrossRef]

13. Hamilton, G.; Rath, B. Repurposing of Anthelminthics as Anticancer Drugs. Oncomedicine 2017, 3, 1-8. [CrossRef]

14. Jones, J.O.; Bolton, E.C.; Huang, Y.; Feau, C.; Guy, R.K.; Yamamoto, K.R.; Hann, B.; Diamond, M.I. Non-Competitive Androgen Receptor Inhibition in vitro and In Vivo. Proc. Natl. Acad. Sci. USA 2009, 106, 7233-7238. [CrossRef] [PubMed]

15. Diamond, M.I.; Jones, J.O; Renslo, A.R. Small-Molecule Inhibitors of the Androgen Receptor. U.S. Patent 8,580,773 B2, 12 November 2013 
16. Beck, J.W.; Saavedra, D.; Antell, G.J.; Tejeiro, B. The Treatment of Pinworm Infections in Humans (Enterobiasis) with Pyrvinium Cloride and Pyrvinium Pamoate. Am. J. Trop. Med. Hyg. 1959, 8, 349-352. [CrossRef] [PubMed]

17. Beck, J.W. Treatment of Pinworm Infections with Reduced Single Dose of Pyrvinium Pamoate. JAMA J. Am. Med. Assoc. 1964, 189, 511. [CrossRef] [PubMed]

18. Wang, C.C.; Galli, G.A. Strongyloidiasis Treated with Pyrvinium Pamoate. J. Am. Med. Assoc. 1965, 193, 191-192. [CrossRef]

19. De Padua Vilela, M.; Zucas, A.W.; Iglesias, J. The Therapy of Trichuriasis with a Combination of Thiabendazole and Pyrvinium Pamoate. J. New Drugs 1965, 5, 86-89. [CrossRef]

20. Downey, A.S.; Chong, C.R.; Graczyk, T.K.; Sullivan, D.J. Efficacy of Pyrvinium Pamoate against Cryptosporidium parvum Infection in vitro and in a Neonatal Mouse Model. Antimicrob. Agents Chemother. 2008, 52, 3106-3112. [CrossRef]

21. Downey, A.S.; Graczyk, T.K.; Sullivan, D.J. in vitro Activity of Pyrvinium Pamoate against Entamoeba histolytica and Giardia intestinalis Using Radiolabelled Thymidine Incorporation and an SYBR Green I-Based Fluorescence Assay. J. Antimicrob. Chemother. 2009, 64, 751-754. [CrossRef]

22. Gaikwad, V.R.; Karale, U.B.; Govindarajalu, G.; Adhikari, N.; Krishna, E.V.; Siva, V.; Misra, S.; Sriram, D.; Sijwali, P.S.; Rode, H.B. Synthesis and Efficacy of Pyrvinium-Inspired Analogs against Tuberculosis and Malaria Pathogens. Biooroganic. Med. Chem. Lett. 2020, 30, 127037. [CrossRef]

23. Sun, Y.; Gao, L.; Yuan, M.; Yuan, L.; Yang, J.; Zeng, T. In Vitro and In Vivo Study of Antifungal Effect of Pyrvinium Pamoate Alone and in Combination with Azoles Against Exophiala dermatitidis. Front. Cell. Infect. Microbiol. 2020, 10, 576975. [CrossRef] [PubMed]

24. Chen, G.; Mulla, W.A.; Kucharavy, A.; Tsai, H.J.; Rubinstein, B.; Conkright, J.; McCroskey, S.; Bradford, W.D.; Weems, L.; Haug, J.S.; et al. Targeting the Adaptability of Heterogeneous Aneuploids. Cell 2015, 160, 771-784. [CrossRef]

25. Jawahar, S.; Tricoche, N.; Bulman, C.A.; Sakanari, J.; Lustigman, S. Drugs That Target Early Stages of Onchocerca volvulus: A Revisited Means to Facilitate the Elimination Goals for Onchocerciasis. PLoS Negl. Trop. Dis. 2021, 15, e0009064. [CrossRef] [PubMed]

26. Kamgno, J.; Pion, S.D.; Chesnais, C.B.; Bakalar, M.H.; D’Ambrosio, M.V.; Mackenzie, C.D.; Nana-Djeunga, H.C.; GounoueKamkumo, R.; Njitchouang, G.R.; Nwane, P.; et al. Test-and-Not-Treat Strategy for Onchocerciasis in Loa loa-Endemic Areas. N. Engl. J. Med. 2017, 377, 2044-2052. [CrossRef]

27. Drugs for Neglected Diseases Initiative (DNDi). Available online: https://dndi.org/research-development/portfolio/ (accessed on 18 December 2021).

28. Wanji, S.; Chunda, V.C.; Fombad, F.F.; Njouendou, A.J.; Gandjui, N.V.T.; Ritter, M.; Enyong, P.A.; Mackenzie, C.; Taylor, M.J.; Hoerauf, A.; et al. Advances in Preclinical Platforms of Loa loa for Filarial Neglected Tropical Disease Drug and Diagnostics Research. Front. Trop. Dis. 2021, 2, 778724. [CrossRef]

29. DNDi. Target Product Profile for River Blindness. Available online: https://dndi.org/diseases/filaria-river-blindness/targetproduct-profile/ (accessed on 18 December 2021).

30. Hoerauf, A.; Nissen-Pähle, K.; Schmetz, C.; Henkle-Dührsen, K.; Blaxter, M.L.; Büttner, D.W.; Gallin, M.Y.; Al-Qaoud, K.M.; Lucius, R.; Fleischer, B. Tetracycline Therapy Targets Intracellular Bacteria in the Filarial Nematode Litomosoides sigmodontis and Results in Filarial Infertility. J. Clin. Investig. 1999, 103, 11-18. [CrossRef] [PubMed]

31. Hoerauf, A.; Mand, S.; Fischer, K.; Kruppa, T.; Marfo-Debrekyei, Y.; Debrah, A.Y.; Pfarr, K.M.; Adjei, O.; Büttner, D.W. Doxycycline as a Novel Strategy against Bancroftian Filariasis-Depletion of Wolbachia Endosymbionts from Wuchereria bancrofti and Stop of Microfilaria Production. Med. Microbiol. Immunol. 2003, 192, 211-216. [CrossRef]

32. Aljayyoussi, G.; Tyrer, H.E.; Ford, L.; Sjoberg, H.; Pionnier, N.; Waterhouse, D.; Davies, J.; Gamble, J.; Metugene, H.; Cook, D.A.N.; et al. Short-Course, High-Dose Rifampicin Achieves Wolbachia Depletion Predictive of Curative Outcomes in Preclinical Models of Lymphatic Filariasis and Onchocerciasis. Sci. Rep. 2017, 7, 210. [CrossRef] [PubMed]

33. Taylor, M.J.; Makunde, W.H.; McGarry, H.F.; Turner, J.D.; Mand, S.; Hoerauf, A. Macrofilaricidal Activity after Doxycycline Treatment of Wuchereria bancrofti: A Double-Blind, Randomised Placebo-Controlled Trial. Lancet 2005, 365, 2116-2121. [CrossRef]

34. Debrah, A.Y.; Mand, S.; Marfo-Debrekyei, Y.; Batsa, L.; Pfarr, K.; Buttner, M.; Adjei, O.; Buttner, D.; Hoerauf, A. Macrofilaricidal Effect of 4 Weeks of Treatment with Doxycycline on Wuchereria bancrofti. Trop. Med. Int. Health 2007, 12, 1433-1441. [CrossRef] [PubMed]

35. Hoerauf, A.; Specht, S.; Buttner, M.; Pfarr, K.; Mand, S.; Fimmers, R.; Marfo-Debrekyei, Y.; Konadu, P.; Debrah, A.Y.; Bandi, C.; et al. Wolbachia Endobacteria Depletion by Doxycycline as Antifilarial Therapy Has Macrofilaricidal Activity in Onchocerciasis: A Randomized Placebo-Controlled Study. Med. Microbiol. Immunol. 2008, 197, 335. [CrossRef] [PubMed]

36. Hoerauf, A.; Specht, S.; Marfo-Debrekyei, Y.; Buttner, M.; Debrah, A.Y.; Mand, S.; Batsa, L.; Brattig, N.; Konadu, P.; Bandi, C.; et al Efficacy of 5-Week Doxycycline Treatment on Adult Onchocerca volvulus. Parasitol. Res. 2009, 104, 437-447. [CrossRef] [PubMed]

37. Specht, S.; Mand, S.; Marfo-Debrekyei, Y.; Debrah, A.Y.; Konadu, P.; Adjei, O.; Büttner, D.W.; Hoerauf, A. Efficacy of 2- and 4-Week Rifampicin Treatment on the Wolbachia of Onchocerca volvulus. Parasitol. Res. 2008, 103, 1303-1309. [CrossRef] [PubMed]

38. Sungpradit, S.; Chatsuwan, T.; Nuchprayoon, S. Susceptibility of Wolbachia, an Endosymbiont of Brugia malayi Microfilariae, to Doxycycline Determined by Quantitative PCR Assay. Southeast. Asian J. Trop. Med. Public Health 2012, 43, 841-850. [PubMed]

39. Debrah, A.Y.; Specht, S.; Klarmann-schulz, U.; Batsa, L.; Mand, S.; Marfo-debrekyei, Y.; Fimmers, R.; Dubben, B.; Kwarteng, A.; Osei-atweneboana, M.; et al. Doxycycline Leads to Sterility and Enhanced Killing of Female Onchocerca volvulus Worms in an 
Area with Persistent Microfilaridermia After Repeated Ivermectin Treatment: A Randomized, Placebo-Controlled, Double-Blind Trial. Clin. Infect. Dis. 2015, 61, 517-526. [CrossRef] [PubMed]

40. Ishii, I.; Harada, Y.; Kasahara, T. Reprofiling a Classical Anthelmintic, Pyrvinium Pamoate, as an Anti-Cancer Drug Targeting Mitochondrial Respiration. Front. Oncol. 2012, 2, 137. [CrossRef] [PubMed]

41. Xu, W.; Lacerda, L.; Debeb, B.G.; Atkinson, R.L.; Solley, T.N.; Li, L.; Orton, D.; McMurray, J.S.; Hang, B.I.; Lee, E.; et al. The Antihelmintic Drug Pyrvinium Pamoate Targets Aggressive Breast Cancer. PLoS ONE 2013, 8, e71508. [CrossRef] [PubMed]

42. Momtazi-Borojeni, A.A.; Abdollahi, E.; Ghasemi, F.; Caraglia, M.; Sahebkar, A. The Novel Role of Pyrvinium in Cancer Therapy. J Cell. Physiol. 2018, 233, 2871-2881. [CrossRef]

43. Guan, Q.; Zhan, L.; Liu, Z.H.; Pan, Q.; Chen, X.L.; Xiao, Z.; Qin, C.; Zhang, X.L. Identification of Pyrvinium Pamoate as an Anti-Tuberculosis Agent in vitro and In Vivo by SOSA Approach amongst Known Drugs. Emerg. Microbes Infect. 2020, 9, 302-312. [CrossRef]

44. Bulman, C.A.; Bidlow, C.M.; Lustigman, S.; Cho-Ngwa, F.; Williams, D.; Rascon, A.A., Jr.; Tricoche, N.; Samje, M.; Bell, A.; Suzuki, B.; et al. Repurposing Auranofin as a Lead Candidate for Treatment of Lymphatic Filariasis and Onchocerciasis. PLoS Negl. Trop. Dis. 2015, 9, e0003534. [CrossRef]

45. Voronin, D.; Tricoche, N.; Jawahar, S.; Shlossman, M.; Bulman, C.A.; Fischer, C.; Suderman, M.T.; Sakanari, J.A.; Lustigman, S. Development of a Preliminary In Vitro Drug Screening Assay Based on a Newly Established Culturing System for Pre-Adult Fifth-Stage Onchocerca volvulus Worms. PLoS Negl. Trop. Dis. 2019, 13, e0007108. [CrossRef] [PubMed]

46. Gunderson, E.L.; Vogel, I.; Chappell, L.; Bulman, C.A.; Lim, K.C.; Luo, M.; Whitman, J.D.; Franklin, C.; Choi, Y.-J.; Lefoulon, E.; et al. The Endosymbiont Wolbachia Rebounds Following Antibiotic Treatment. PLoS Pathog. 2020, 16, e1008623. [CrossRef] [PubMed] 